Molecules 2003, 8,1

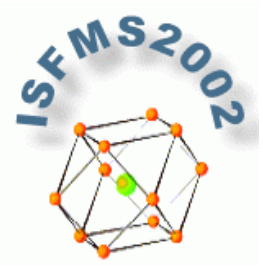

molecules

ISSN 1420-3049

http://www.mdpi.org

\title{
Editorial
}

\section{Special Issue: Selected Papers from the International Symposium on Frontiers in Molecular Science (ISFMS 2002)}

\author{
Shu-Kun Lin ${ }^{1,2}$ and Derek J. McPhee ${ }^{3}$ \\ ${ }^{1}$ Molecules Editorial Office, Ocean University of China, Qingdao 266003, Shandong Province, P.R. China. \\ Tel. \& Fax: (+86) 532 203-1522; Tel.: (+86) 532 203-1860 (office direct); E-mail: linsk@ ouc.edu.cn, \\ ${ }^{2}$ Molecular Diversity Preservation International (MDPI), Matthaeusstrasse 11, CH-4057 Basel, Switzerland. \\ Tel.: (+41) 79 322-3379; Fax: (+41) 61 302-8918; E-mail: lin@mdpi.org, http://www.mdpi.org/lin \\ ${ }^{3}$ Brantford Chemicals Inc., 34 Spalding Dr., Brantford, ON, N3T 5W5, Canada. Tel.: (+1) 519 756- 8942, xt \\ 4992; Fax: (+1) 519 753-3051; E-mail: mcphee@mdpi.org
}

We are pleased to launch Volume 8 of Molecules with a special issue containing a selection of lectures and papers presented at the ISFMS 2002 conference, co-sponsored by MDPI and hosted by the Ocean University of China last July 2002 at Qingdao, P.R China [1]. We are especially honoured to present the text of the Science and Society Lecture given by the 1991 Nobel Laureate in Chemistry, Professor Dr. Richard Ernst (ETH, Switzerland).

The other 20 papers in this issue are expanded, peer-reviewed versions of some of the presentations given at the conference, which represent a cross-section of current research taking place on the frontiers of molecular science. Additional papers from the conference will be published in forthcoming issues as they become available.

\section{Reference}

1. Lin, S-K; Li, X. The International Symposium on Frontiers in Molecular Science 2002 (ISFMS 2002), Qingdao, China, July 15-18, 2002. Molecules 2002, 7, 854.

(C) 2003 by MDPI (http://www.mdpi.org). Reproduction is permitted for noncommercial purposes. 